\title{
Fission product iodine release and retention in nuclear reactor accidents - experimental programme at PSI $^{*}$
}

\author{
H. BRUCHERTSEIFER, R. CRIPPS, S. GUENTAY, B. JAECKEL \\ Department for Nuclear Energy and Safety (NES), Paul Scherrer Institute (PSI), Villigen and \\ Würenlingen, Switzerland
}

Iodine radionuclides constitute one of the most important fission products of uranium and plutonium. If the volatile forms would be released into the environment during a severe accident, a potential health hazard would then ensue. Understanding its behaviour is an important prerequisite for planning appropriate mitigation measures. Improved and extensive knowledge of the main iodine species and their reactions important for the release and retention processes in the reactor containment is thus mandatory. The aim of PSI's radiolytical studies is to improve the current thermodynamic and kinetic databases and the models for iodine used in severe accident computer codes.

Formation of sparingly soluble silver iodide (AgI) in a PWR containment sump can substantially reduce volatile iodine fraction in the containment atmosphere. However, the effectiveness is dependent on its radiation stability. The direct radiolytic decomposition of $\mathrm{AgI}$ and the effect of impurities on iodine volatilisation were experimentally determined at PSI using a remote-controlled and automated high activity ${ }^{188} \mathrm{~W} / \mathrm{Re}$ generator $(40 \mathrm{GBq} / \mathrm{ml})$. Low molecular weight organic iodides are difficult to be retained in engineered safety systems. Investigation of radiolytic decomposition of methyl iodide in aqueous solutions, combined with an on-line analysis of iodine species is currently under investigation at PSI.

\section{Introduction}

Iodine radionuclides are generated in large amounts in fuel as important fission products of uranium and plutonium during nuclear power plant (NPP) operations. Their release, especially the isotopes ${ }^{131} \mathrm{I}$ and the long-lived ${ }^{129} \mathrm{I}$ (half-life $10^{7}$ years), into the containment and more importantly into the environment during a severe NPP accident, due to uncontrolled leakage, represent a significant health hazard. Understanding its behaviour in reactor containment is an important prerequisite to plan appropriate mitigation measures. Iodine behaviour depends on the prevailing conditions. For example, different iodine species will exist in the reactor accident sump water, in containment venting scrubber solutions and filters. Detailed knowledge of the main iodine species and their reactions taking part in the release and retention processes in the reactor containment is thus mandatory (see chapter 2).

Thermodynamic and kinetic databases of numerous iodine reactions in aqueous and gaseous phases have been developed and integrated in computer codes predicting severe accident iodine chemical and physical behaviour (such as PSI's IMPAIR code $[1,2]$ ).

A brief overview is given on recent and current experimental PSI studies, specifically to predict the processes leading to molecular iodine formation and destruction in the

\footnotetext{
${ }^{*}$ The authors would like to thank the Commission for the Operation of Swiss Nuclear Power Plants (UAK) and the Swiss Federal Bureau for Education and Science (BBW) for the financial support.
} 
sump prior to release into the containment atmosphere during an accident. For example, silver aerosol, if released, in severe accident conditions from degraded pressurised water reactor (PWR) control rods into the containment atmosphere, followed by settling into the sump, can effectively trap and thus reduce the volatile iodine fraction in the containment atmosphere. Sparingly soluble silver iodide (AgI) is formed. A considerable volume of knowledge has already been accumulated regarding general gaseous and aqueous iodine chemistry, with and without a radiation field; an overview is given in [3]. However, the integral effect of the prevailing $\beta$-radiation field on the stability of the silver iodide formed under reactor accident conditions is not sufficiently understood to remove all doubts concerning the suitability of silver metal to act as a sink for fission product iodine. Iodine also reacts with organic materials (e.g. paint surfaces and products from decomposing cables) forming volatile organoiodines, which are difficult to be removed by containment venting filters or in the leakage paths. Studies at PSI aim to achieve a valuable insight into $\mathrm{AgI}$ stability and organoiodine decomposition in order to inhibit iodine volatilisation from a reactor containment sump.

The research has been performed mainly within the framework of international nuclear reactor safety projects. The Phebus FP Programme, for example, provides in a large international co-operation, a unique source of data on fission product release, transport and chemical behaviour under prototypic core degradation, which are required for code development and assessment.

\section{Iodine containment reactions in nuclear reactor accidents}

Fission products, fuel particles, control rod and structural materials (metals, boron, organics, etc.) are released during a severe accident involving core damage with a partial melting of fuel. As a result of loss of integrity of the reactor coolant system water (including its contents: boric acid, alkaline metals etc.) is released in the containment forming the sump.

The released material can undergo various reactions with a) the components of the containment: atmosphere (oxygen, nitrogen and steam), b) the paint, steel and concrete, and $\mathrm{c}$ ) the cable pyrolysis products. Reactions with secondary products also take place, e.g., with hydrogen, nitrogen oxides, acids (nitric, hydrochloric, sulphuric). The sump formed due to the cooling water, condensed steam and spray droplets constitutes an aqueous solution/suspension at the bottom of the containment (see Fig. 1).

The radiation induces chemical reactions in the gas phase, on the solid surfaces (walls) and in the aqueous phase. As a result, numerous species of the fission product iodine with the main isotopes of ${ }^{127} \mathrm{I},{ }^{129} \mathrm{I}$ and ${ }^{131} \mathrm{I}$ (fission yields ${ }^{*}$ of $0.1233,0.7787$ and 2.885 , respectively) are formed. Iodide, iodate, molecular and organoiodines (methyl iodide and other) or their sorption products are the most stable and detectable products.

In order to obtain integral experimental data on these global interactions in containment under severe accident conditions, an international long-term research programme, called PHEBUS FP, was started in 1988. It is accompanied with other international supportive research programmes to provide detailed separate-effect data.

\footnotetext{
${ }^{*}$ Cumulative chain yield for the thermal neutron fission of ${ }^{235} U$
} 


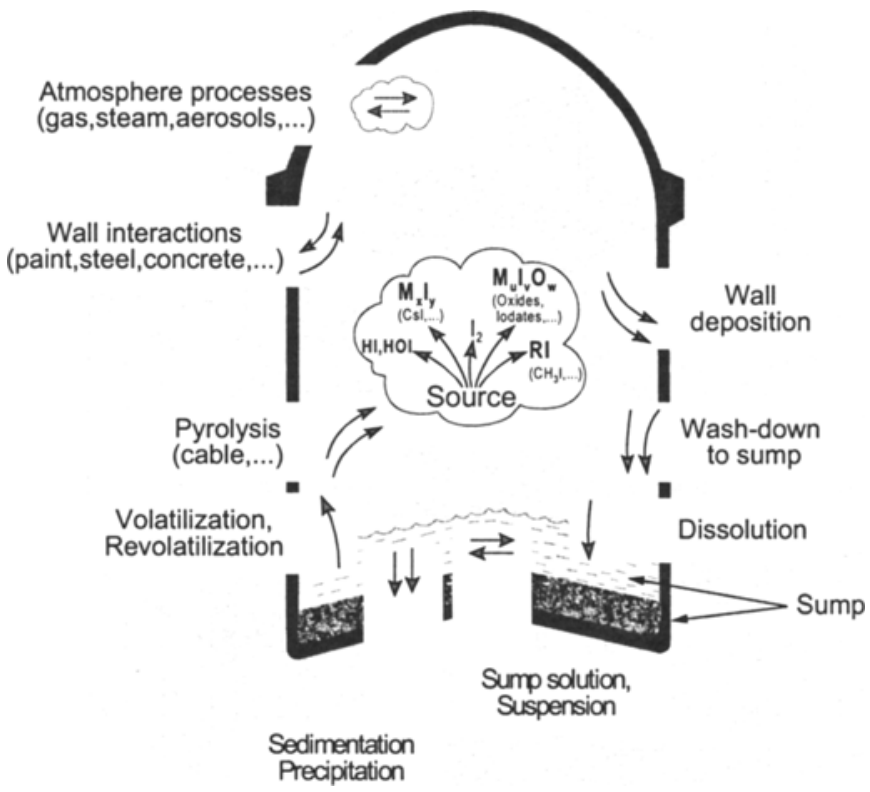

Fig. 1. Scheme of possible interactions, proceeding during a severe reactor accident

\section{Large scale accident-modelling experiments - the PHEBUS FP Programme}

The PHEBUS Fission Product (FP) programme is an important international, severeaccident research activity conducted by the Institute de Protection et de Sûreté Nucléaire (IPSN) in Cadarache, France [4]. Hypothetical, severe reactor accident simulations are conducted in several tests. The data from these tests are still being used to benchmark computer codes used for nuclear plant accident analyses.

In the research reactor PHEBUS, located in Cadarache France, fresh and irradiated fuel rod bundle with a control rod or a debris bed are subjected to extensive degradation. Transport and behaviour of the fission products, actinides and structural materials are investigated in a circuit representative of the reactor coolant system including pipes, a steam generator simulator and a model containment (see Fig. 2). The key parameters of the experiments are summarised in Table 1. The main results concerning the iodine behaviour from the already conducted PHEBUS FP Tests (FPT) can be summarised as follows: Most of iodine inventory was released into the containment (FPT1: 63\%) of which the largest fraction, after washing, deposited and remained in the sump (FPT1: $32 \%$ of inventory). Significant amount of gaseous iodine presence in the reactor containment: up to $30 \%$ in Test FPT0, 3\% in FPT1. Volatile organic iodide is the major fraction of the gaseous iodine in containment atmosphere under steam rich conditions (FPT0/1). 

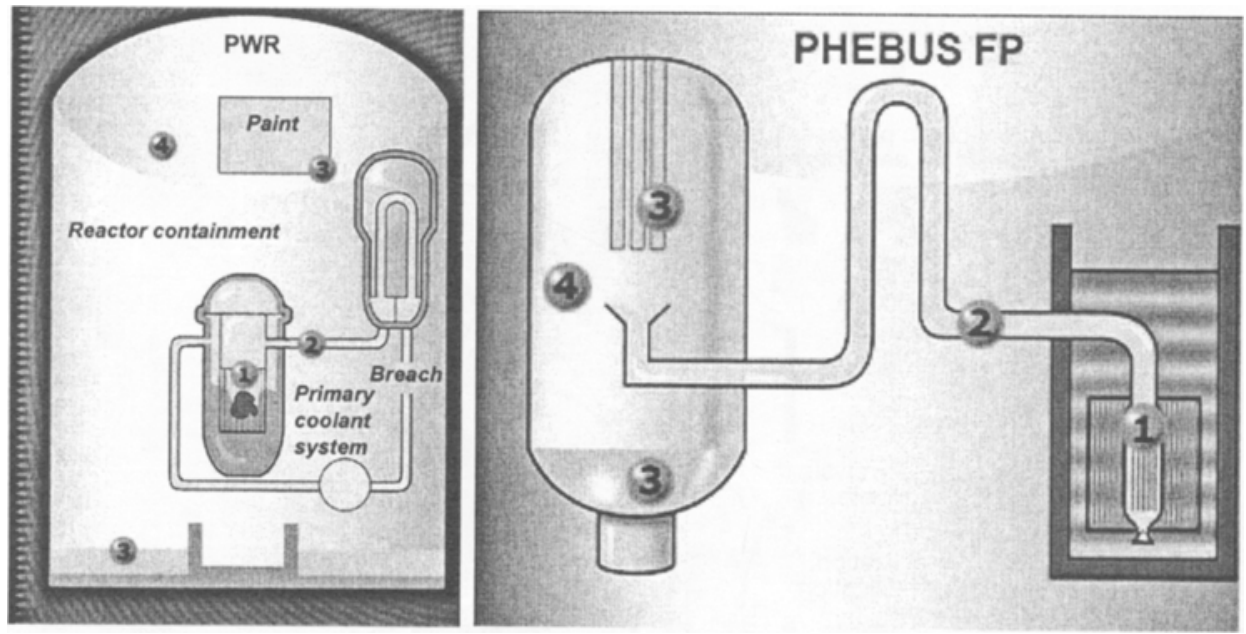

Fig. 2. Outline of the PHEBUS FP Experiments [5]

This is explained by the reaction of $\mathrm{I}_{2}$ with paints on containment condenser surface. $\mathrm{I}_{2}$ is the major fraction of the gaseous iodine in containment atmosphere under steam poor conditions (FPT2). FPT0/1: Low release of $\mathrm{I}_{2}$ from the sump at $\mathrm{pH} 5$ due to the effective trapping by silver released from the control rods; long-term constant but steady low release. FPT2: Decreasing release of $\mathrm{I}_{2}$ from the sump at $\mathrm{pH} 9$ to a level of almost zero release; less effectiveness of silver for iodine trapping; significant amount of dissolved iodine species in the sump. The tests have indicated that it is very important to know iodine speciation and their distribution inside the containment.

PSI has contributed to the definition (FPT3), the data interpretation of the tests, and makes also contributions, using its experience and facilities, in the form of experimental work with and without radiation and by modelling of the anticipated progression of the reactor accident.

Table 1. PHEBUS FP Test Parameters.

\begin{tabular}{|c|c|c|c|c|}
\hline Test & Fuel & $\begin{array}{c}\text { Experimental } \\
\text { parameter/steam }\end{array}$ & Containment & Date \\
\hline FPT0 & $\begin{array}{l}\text { Fresh, trace irradiated } \\
1 \mathrm{Ag}-\mathrm{In}-\mathrm{Cd} \text { control } \\
\text { rod }\end{array}$ & $\begin{array}{l}\text { Steam rich } \\
\text { (oxidizing) }\end{array}$ & $\begin{array}{ll}\text { Acidic sump } & (\mathrm{pH} \mathrm{5}) \\
\text { "Cold" sump } & \left(90^{\circ} \mathrm{C}\right)\end{array}$ & 02.12 .1993 \\
\hline FPT1 & $\begin{array}{l}\text { BR3 23GWd/tU } \\
\text { I Ag-In-Cd control } \\
\text { rod }\end{array}$ & $\begin{array}{l}\text { Steam rich } \\
\text { (oxidizing) }\end{array}$ & $\begin{array}{ll}\text { Acidic sump } & (\mathrm{pH} 5) \\
\text { "Cold" sump } & \left(90^{\circ} \mathrm{C}\right)\end{array}$ & 26.07 .1996 \\
\hline FPT2 & $\begin{array}{l}\mathrm{BR} 332 \mathrm{GWd} / \mathrm{tU} \\
1 \mathrm{Ag}-\mathrm{In}-\mathrm{Cd} \text { control } \\
\text { rod }\end{array}$ & $\begin{array}{l}\text { Steam poor } \\
\text { (reducing) }\end{array}$ & $\begin{array}{ll}\text { Alkaline sump } & (\mathrm{pH} \mathrm{9}) \\
\text { "Hot" sump } & \left(120^{\circ} \mathrm{C}\right)\end{array}$ & 12.10 .2000 \\
\hline FPT3 & $\begin{array}{l}\mathrm{BR} 324 \mathrm{GWd} / \mathrm{tU} \\
1 \mathrm{~B}_{4} \mathrm{C} \text { control rod }\end{array}$ & $\begin{array}{l}\text { Analogous to } \\
\text { FPT2 }\end{array}$ & Analogous to FPT2 & $\begin{array}{l}\text { Scheduled } \\
\text { for } 2003\end{array}$ \\
\hline FPT4 & $\begin{array}{l}\text { EDF-fuel (Graveline) } \\
38 \mathrm{GWd} / \mathrm{tU}, \mathrm{ZrO}_{2}\end{array}$ & $\begin{array}{l}\text { Debris bed } \\
\text { (release of low } \\
\text { volatiles) }\end{array}$ & Not considered & 22.07 .1999 \\
\hline
\end{tabular}




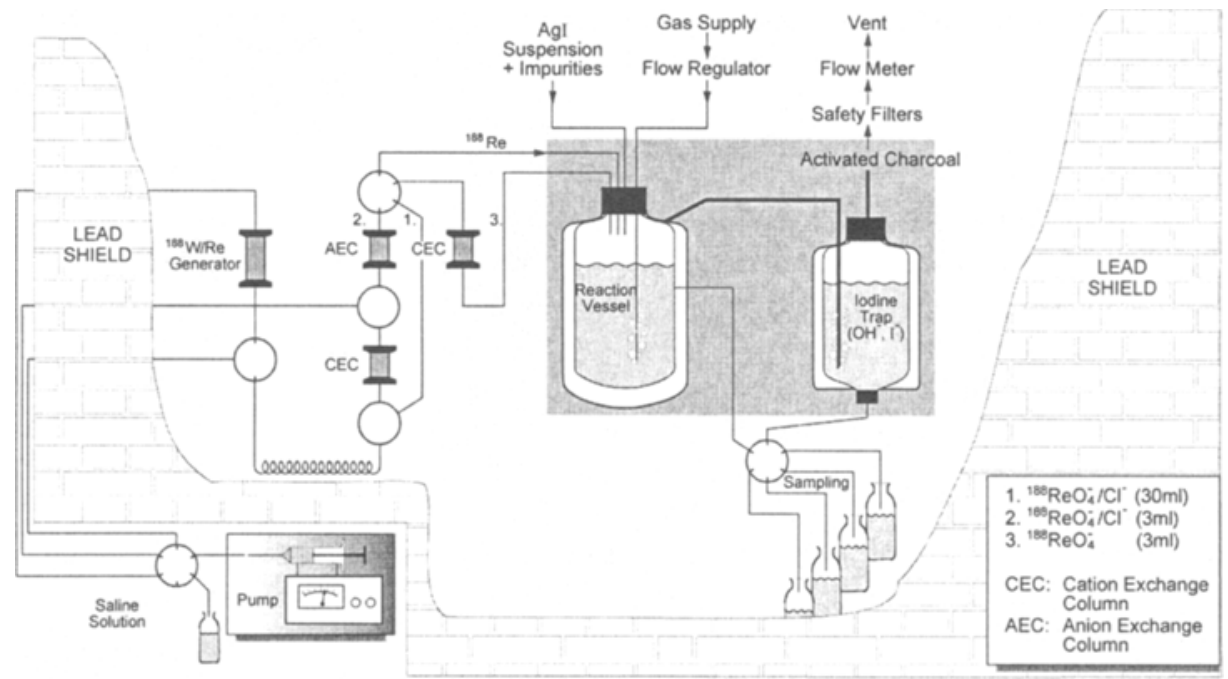

Fig. 3. Remote controlled pressurised elution of Re from a W/Re-generator for the study of AgI stability under $\beta$-radiation (schematic diagram of the FENRIS facility)

\section{Radiolysis studies}

Large amounts of silver in aerosol form were released in the two first PHEBUS tests, i.e. FPT0 [6] and FPT1 [7]. The results of these tests indicate that relatively high and stable volatile iodine concentrations persisted in the containment atmosphere especially after the washing phase, despite the presence of excessive amount of silver in the sump. The cause of the unexpected high iodine concentration in the containment atmosphere has not yet been identified. A possible contribution as a result of radiolytic decomposition of colloidal AgI under mainly $\beta$-irradiation could not be fully excluded based on current measurements and available information. Consequently, as part of the Swiss contribution to the Phebus Programme, an experimental project was started in 1998 to assist the interpretation of the results of the PHEBUS tests containing silver and to provide basis information about the radiolytic decomposition of $\mathrm{AgI}$ under prototypical conditions.

\subsection{Laboratory investigations using in-situ $\beta$-irradiation at realistic dose rate}

$\beta$-irradiation is a major contribution in the radiation field in the sump. ${ }^{188} \operatorname{Re}$ is a $\beta$ emitting nuclide and in dissolved perrhenate $\left({ }^{188} \mathrm{ReO}_{4}{ }^{-}\right)$ions form, with an initial concentration of $\max .40 \mathrm{GBq} / \mathrm{mL}$ in water, can constitute the representative radiation source in a simulated sump. A high activity (about $110 \mathrm{GBq}$ ) ${ }^{188} \mathrm{~W} / \mathrm{Re}$ generator is used to elute the radionuclide ${ }^{188} \mathrm{Re}$ for in-situ irradiation. An automated and remotely controlled facility, called FENRIS [8], was designed. A reaction vessel, an iodine trap, a sampling unit, an elution and activity concentration system as shown in Fig. 3) are the main components of the facility. A gas spraying and venting systems, a PC-based process control and the 
data acquisition unit are the peripheral components. The facility is used to irradiate caesium iodide solutions and silver iodide colloidal suspensions.

\subsection{Radiation stability of aqueous silver iodide suspensions}

The formation of sparingly soluble silver iodide (AgI) in a pressured water reactor sump can extensively reduce the iodine volatility from the sump due to silver affinity for iodine. However, the integral effect of the prevailing $\beta$-irradiation field on the radiolytic stability of the silver iodide might hinder the anticipated sink effect of silver.

The main PSI irradiation experimental results have established that the AgI radiolysis can potentially increase volatile iodine release into the containment gas atmosphere due to various mechanisms, which were investigated for the first time. These are the direct radiolytic decomposition of AgI colloid (see Fig. 4), acidification of the sump solution by acid generation, e.g., nitric acid (product of air radiolysis in containment), sulphuric or hydrochloric acid (decomposition of cables), enhanced oxidation potential of the sump solution because of nitrate radiolysis and dissolved nitrogen oxides and the presence of impurities, e.g. of chloride ions at low $\mathrm{pH}$. Depending on the conditions a small to important iodine release from an irradiated aqueous silver iodide suspension can occur under prototypical severe accident conditions.

The results of the experiments are used for enhanced modelling [9] of iodine radiation chemistry. The model includes the radiolytic AgI decomposition by dissociation and the direct effects (AgI surface - $\mathrm{OH}$ radical reactions, $\beta$-interactions, etc.). It covers specifically the acidic sump and strong oxidation conditions as well as the effect of the nitrate, chloride and silver constituents of the sump.

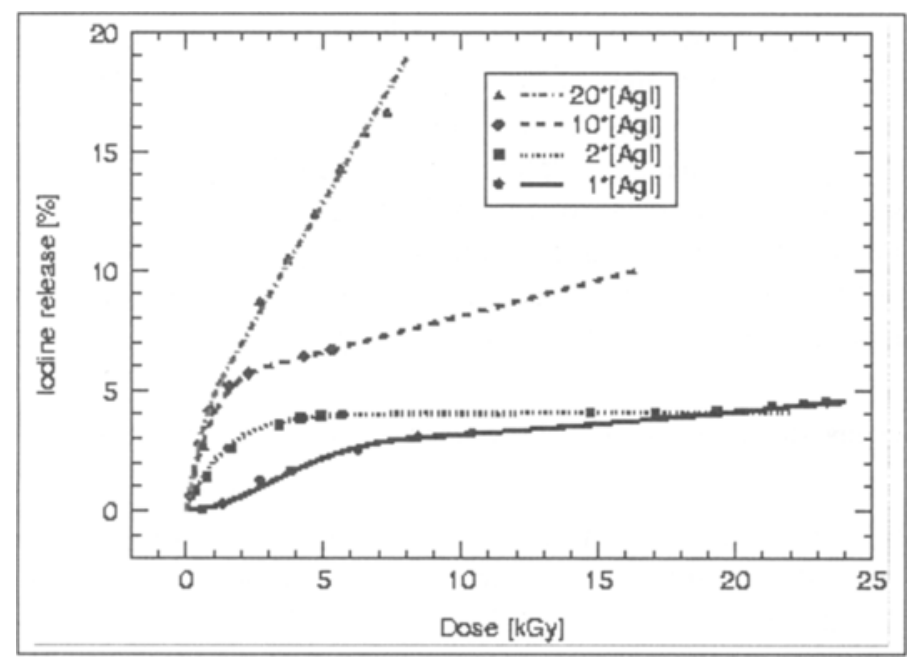

Fig. 4. The fraction of released volatile iodine is proportional to the concentration of suspended (undissolved) AgI under otherwise the same conditions. The results show that decomposition by direct surface oxidation of iodide ions on the AgI particles takes place [8]. 


\section{Mitigation of formation of gaseous iodine in containment}

The desired concept of mitigation of formation of gaseous iodine species currently relies on the destruction of the formed molecular iodine and organic iodide. However, several important processes leading to the destruction of volatile forms of iodine are not studied or not well quantified. The iodine behaviour in the nuclear reactor containment and the interaction with its components, are, to a large extent, still unknown. An improved knowledge of the destruction mechanisms and reaction rates will allow their importance to be assessed in terms of natural mitigation processes and accident management interventions. An understanding of these specific accident effects will allow data and models developed mainly for PWR systems to be applied with confidence to boiling water reactor (BWR) source term predictions. The aim of the international ICHEMM project [10] as part of the European Commission 5th EURATOM Framework Programme is to provide contributions to further understanding of iodine mitigation mechanisms.

\subsection{Iodine chemistry and mitigation mechanisms (ICHEMM project)}

The proposed work programme comprises the following main elements. Provision of new and improved thermodynamic and kinetic data related to iodine decomposition or transmutation reactions, which are not yet included in prediction codes for severe accident iodine behaviour. This will involve experimental measurements of the rate of molecular iodine destruction by ozone in the gas phase and of the rate of methyl iodide decomposition under irradiation in the gaseous and aqueous phases.

Included are experimental studies of the effects of candidate additive materials on iodine volatility from irradiated iodine solutions. The identified mechanisms have to be quantified for application in mitigation procedures on representative accident sequences.

\subsection{Study of the decomposition of aqueous organic iodides at PSI}

One of the most important objectives is to study the decomposition processes of dissolved organic iodides for their retention in an aqueous phase. Therefore, work at PSI, within the ICHEMM project, has begun to investigate aqueous decomposition processes (hydrolysis and radiolysis) of volatile methyl iodide and development of models for result interpretation. Low molecular weight organic iodides, i.e. methyl iodide, formed as result of paint - molecular iodine, or organic radicals with iodine reaction in sump.

The objectives of the radiolysis studies are to quantify the rate of organic iodine destruction under the reactor relevant conditions, and to investigate the use of candidate additives to promote the decomposition of organic iodine and its retention in non-volatile aqueous forms to develop an accident management procedure for the reduction of the volatile organoiodine in the containment atmosphere by application of a suitable additive to the containment sump.

Aqueous and buffered solutions of methyl iodide are being investigated at controlled temperature and containing a dissolved chemically inert radionuclide $\left({ }^{188} \mathrm{Re}\right.$ in the form of $\mathrm{ReO}_{4}^{-}$) for high dose rate (up to $0.8 \mathrm{~Gy} / \mathrm{s}$ ) in-situ $\beta$-irradiation and in the presence or absence of oxygen. 

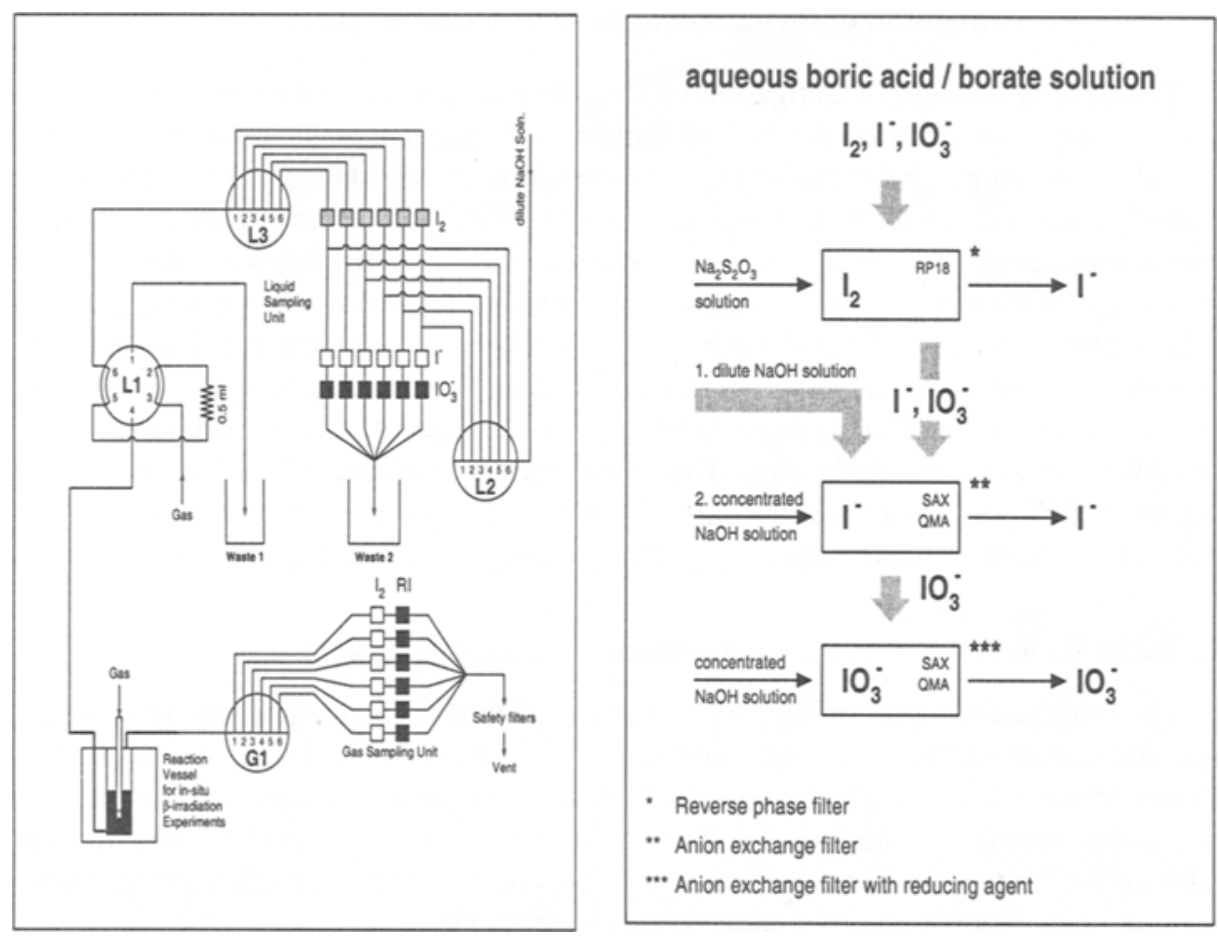

Fig. 5. Iodine species analysis (set-up and separation scheme).

A prerequisite for the investigations is the availability of analytical methods for the iodine species in the gas and aqueous phases.

\subsection{Analysis of iodine reaction products}

A fast procedure for analysis of iodine species, products of radiolysis, was developed, tested and introduced into experimental practice. During the experiments to study the methyl iodide decomposition, on-line filters carry out sampling and separation of one or more iodine species. Volatile iodine species (organoiodide, RI, and molecular iodine, $\mathrm{I}_{2}$ ) are sparged from solution and adsorbed in solid phase filters (gas sampling unit). Aqueous samples containing dissolved iodine species are directly passed into sorption and ion exchange filters to effect separation of $\mathrm{I}_{2}, \mathrm{I}^{-}$and $\mathrm{IO}_{3}{ }^{-}$. The employed methyl iodide is tagged with ${ }^{131}$ I to measure their activities for mass determination (see Fig. 5).

Experiments to study the radiolysis, hydrolysis and the secondary reactions using the PSI-developed in-situ irradiation facility and iodine species separation procedure for methyl iodide, molecular iodine, iodide and iodate will provide data for the description of the main reaction paths. The data will be included in the corresponding iodine prediction codes. 


\section{Conclusions}

The study of the iodine release and retention mechanisms to favour the conversion of volatile iodine species to non-volatile forms under severe accident conditions is an important part of the current nuclear safety research. It is directed to discover materials and reactions to fix the fission product iodine wastes by complex formation and sorption reactions. At the same time, it serves to develop and validity the probability safety analysis (PSA) of appropriate mitigation strategies and accident management measures.

The research at PSI has provided important aspects of radiolytic stability of AgI on the potential release from the sump. The enhanced aqueous iodine radiation model developed at PSI contributes greatly the assessment of the safety of operating nuclear power plants. The current investigations on the destruction of organic iodide in aqueous phase will further contribute to the safety improvement.

\section{References}

[1] Cripps R., Furrer M., Hellmann S. and Funke F.: PSI Report Nr. 114, Villigen, Switzerland, 1992.

[2] Güntay S. and Cripps R.: PSI Report Nr. 128, Villigen, Switzerland, 1992.

[3] Neeb K. H.: The Radiochemistry of Nuclear Power Plants with Light Water Reactors, Walter de Gruyter, Berlin, New York, 594-641 (1997).

[4] Krischner W. and Rubinstein M. C.: The Phebus Fission Product Project, Elsevier Applied Science, London and New York (1992).

[5] PHEBUS - FP Programme, Testing for better safety, Institut de Protection et de Surete Nucleaire, DRS, CD-ROM, Cadarache, France, 2001.

[6] Jacquemain D. et al.: IPSN Rapport SEA 1/99, Cadarache, France, 1999.

[7] Jacquemain D. et al.: IPSN Rapport SEA 1/00, Cadarache, France, 2000.

[8] Güntay S., Bruchertseifer H., Cripps R. and Jäckel B.: IPSN rapport TG 390 SAWG 00/009, Cadarache/France, 2002.

[9] Cripps R., Bruchertseifer H. and Guentay S.: PSI Scientific Report 2001/Volume IV, Nuclear Energy and Safety pp 69-78, Villigen/Switzerland, 2002.

[10] Dickinson S. et al.: FISA-2001 - EU Research in Reactor Safety, Luxembourg, 12-14 November 2001 FIKS-CT1999-00008, 2001. 